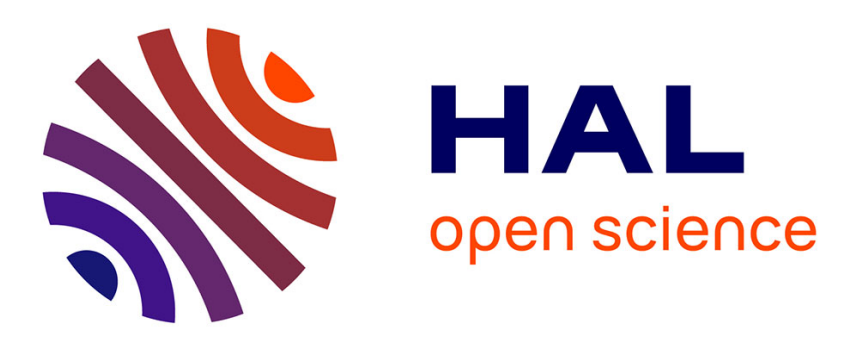

\title{
Characteristics and energy balance of a plasma column sustained by a surface wave
}

\author{
M. Chaker, P. Nghiem, E. Bloyet, Ph. Leprince, J. Marec
}

\section{To cite this version:}

M. Chaker, P. Nghiem, E. Bloyet, Ph. Leprince, J. Marec. Characteristics and energy balance of a plasma column sustained by a surface wave. Journal de Physique Lettres, 1982, 43 (3), pp.71-75. 10.1051/jphyslet:0198200430307100 . jpa-00232011

\section{HAL Id: jpa-00232011 https://hal.science/jpa-00232011}

Submitted on 1 Jan 1982

HAL is a multi-disciplinary open access archive for the deposit and dissemination of scientific research documents, whether they are published or not. The documents may come from teaching and research institutions in France or abroad, or from public or private research centers.
L'archive ouverte pluridisciplinaire HAL, est destinée au dépôt et à la diffusion de documents scientifiques de niveau recherche, publiés ou non, émanant des établissements d'enseignement et de recherche français ou étrangers, des laboratoires publics ou privés. 


\title{
Characteristics and energy balance of a plasma column sustained by a surface wave
}

\author{
M. Chaker, P. Nghiem, E. Bloyet, Ph. Leprince and J. Marec \\ Laboratoire de Physique des Gaz et des Plasmas (*), \\ Bâtiment 212, Université Paris XI, Centre d’Orsay, 91405 Orsay, France
}

(Reçu le 22 septembre 1981, accepté le 10 décembre 1981)

\begin{abstract}
Résumé. - Dans cet article, nous étudions un plasma créé par une onde de surface. L'évolution longitudinale de la densité électronique est décrite et un bilan énergétique est effectué. Nous avons également calculé la fréquence de collision effective pour chaque condition expérimentale.

Abstract. - In this paper, we consider the case of a travelling surface wave sustaining a plasma column acting as the propagating medium. The axial electron density distribution is investigated and the energy balance of the electron gas is established. We have also determined the effective collision frequency for each experimental condition.
\end{abstract}

1. Introduction. - The propagation of electron surface waves can be used to sustain long plasma columns via a surfatron or a surfaguide [1]. To describe the axial electron density $n(z)$ of this plasma column, a theoretical model has been developed [2]. It is based on

- the surface wave dispersion properties,

- the assumption that the wave power absorbed over a given axial length of plasma column is proportional to the number of electrons produced over the same length, the proportionality constant $\theta$ being independent of the wave power. So we have :

$$
P_{\mathrm{abs}}(\Delta z)=\theta S \int_{z}^{z+\Delta z} n(z) \mathrm{d} z
$$

where $P_{\text {abs }}(\Delta z)$ is the wave power absorbed over the axial length $(z, z+\Delta z), S$ the plasma cross section and $n(z)$ the electron density. Application of relation (1) to successive slabs of the column leads to a relation giving the longitudinal variations of electron density :

$$
\frac{\mathrm{d} n}{\mathrm{~d} z}=\frac{-2 \alpha n}{1-\frac{n}{\alpha} \frac{\mathrm{d} \alpha}{\mathrm{d} n}}
$$

$\left(^{*}\right)$ Laboratoire associé au C.N.R.S. 
where $\alpha$ is the wave attenuation coefficient given by the dispersion relation. For a tube structure, the attenuation depends only on the electron-neutral collision frequency for momentum transfer $v$ and the electron density. Thus, $\alpha$ may be written in the form

$$
\alpha=v f(n) .
$$

The value of $f(n)$ can be calculated from the surface wave dispersion equation for any value $n$. To solve equation (2), we have to know the initial condition (i.e., density at $z=0$ ), thus the value of $\theta$. The physical meaning of $\theta$ is the following : $\theta$ is the mean power necessary to the creation of an electron. It may be expressed in the following form :

$$
\theta=v_{\mathrm{i}} e V_{\mathrm{i}}+\frac{3 m}{M} \times \frac{v}{v_{\mathrm{i}}} k T_{\mathrm{e}}+\sum_{0} \frac{v_{\mathrm{j}}}{v_{\mathrm{i}}} e V_{\mathrm{j}}
$$

where $v_{\mathrm{i}}$ is the ionization frequency depending on the electric field, $V_{\mathrm{i}}$ the ionization potential, $V_{\mathrm{j}}$ the potential of the $\mathrm{j}$ excitation level, $v_{\mathrm{j}}$ the frequency of collisions leading to $\mathrm{j}$ level, $m$ and $M$ the masses of electron and ion. The three terms of (4) can be interpreted as loss terms. The first term corresponds to losses by ionizing collisions, the second term to losses by elastic collisions and the third term to losses by collisions leading directly to a $\mathrm{j}$ level.

2. Experimental procedure. - To generate a plasma we have used the surfaguide at $2450 \mathrm{MHz}$ [1]. The experimental arrangement is shown on figure 1. A moving probe enables us to measure the electric field decrease and phase variation of the wave. If we assume that the dispersion relation is verified [4]

$$
\frac{\omega}{\omega_{\mathrm{p}}}=g(\beta) \text { for fixed } \omega
$$

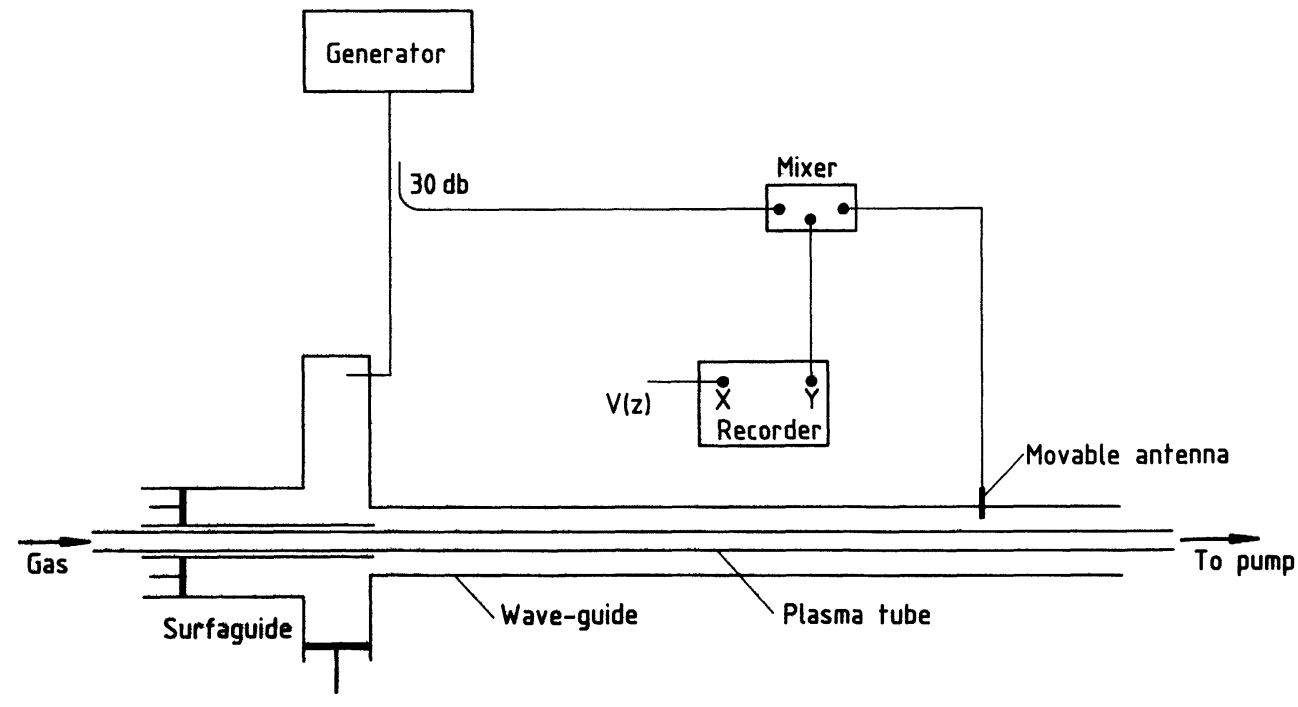

Fig. 1. - Experimental set-up.

where $\omega$ is the wave angular frequency, $\omega_{\mathrm{p}}$, the electron plasma angular frequency and $\beta$, the real part of the wave vector, we can determine the average electron density along the plasma column. The real part of the wave vector is measured through u.h.f. interferogram. Then $\omega_{p}$ is calculated 
from the dispersion diagram (Eq. (5)). The measurements were performed for different radii $(a=0.45 \mathrm{~cm}, a=0.3 \mathrm{~cm})$ and incident powers with argon gas in the pressure range from $50 \mathrm{mtorr}$ to 20 torr.

3. Results and discussion. - Figure 2 gives the axial electron density distribution for three different total absorbed powers. The end of the plasma column has been taken for the starting point. The symbol $(\Gamma)$ represents the initial electron density and the plasma length obtained for every u.h.f. power. The density at the gap increases with the total absorbed power, but the axial density profile is always the same. This behaviour is in agreement with the results of the theoretical model [2] which predict that the slope of the $n(z)$ curve does not depend on the power if all other conditions (collision frequency, plasma diameter, wave frequency) are the same.

From the experimental profile $n(z)$, we have determined the number of electrons created in a slab $\Delta z$ of the column and the power absorbed in this slab. From $n(z)$ and the power decrease

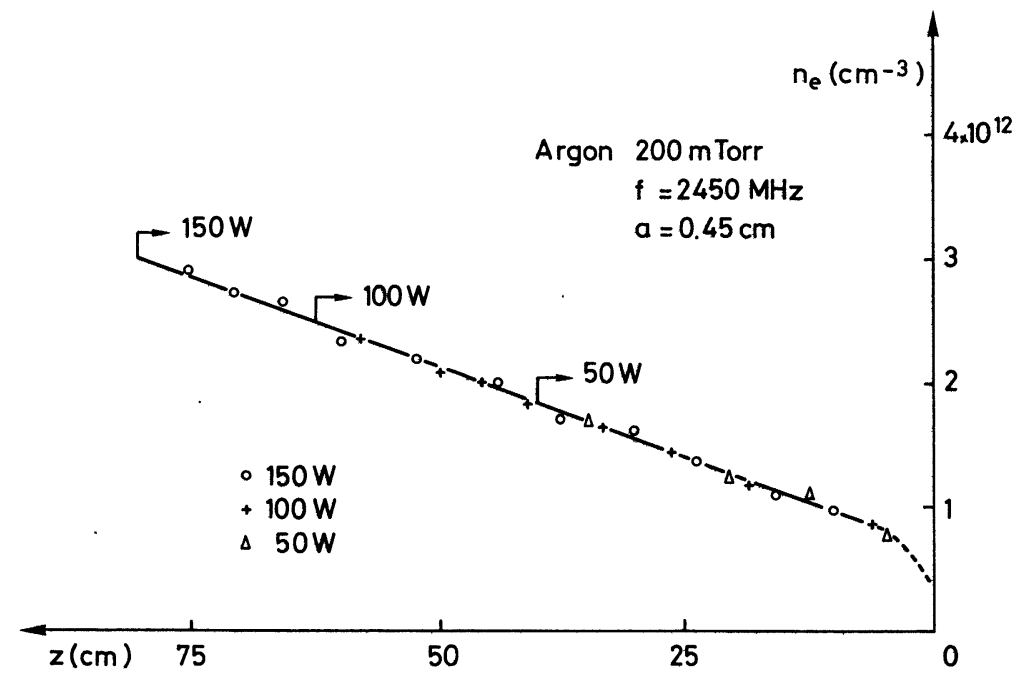

Fig. 2. - Measured axial distribution of the electron density as a function of position from the end of the plasma column for different values of the total absorbed power.

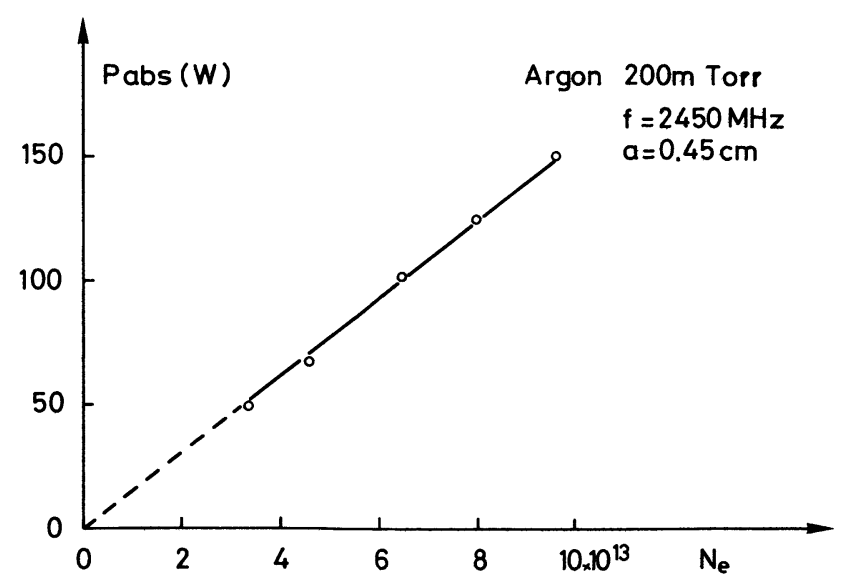

Fig. 3. - Total absorbed power $v s$. the number of electrons produced in the plasma column. 
$P(z)$, we have deduced the total number $N_{\mathrm{e}}$ of electrons in all the plasma column and the absorbed power.

From relation (1), we can obtain values of $\theta$ along the column. We find, as expected, that $\theta$ is constant, i.e., it does not depend on the $z$ coordinate. By plotting the variations of $N_{\mathrm{e}}$ versus those of the total absorbed power (Fig. 3), we verify that $\theta$ is also independent of the input power. The slope of the straight line enables us to determine $\theta$. Its value decreases with the pressure except for high pressures (Fig. 4). The solid line curve represents an empirical law $\left(\theta=p^{-0.75}\right)$.

For given discharge conditions, the application of the theoretical model enables us to get a value for the collision frequency $v$ from the equations (2) and (3). The values of $v$ are plotted as a function of pressure in figure 5 for different radii. Moreover the average electron temperature $T_{\mathrm{e}}$ was estimated from the collision frequency assuming that the electron energy distribution is Maxwellian [3], [5]. The dependence of $T_{\mathrm{e}}$ on $\mathrm{pa}$ is shown in figure 6. The solid line curve represents the electron temperature obtained in the positive column of a glow discharge. One can see that $T_{\mathrm{e}}$ in microwave discharge is close to that of the positive column at pressure lower than 1 torr.

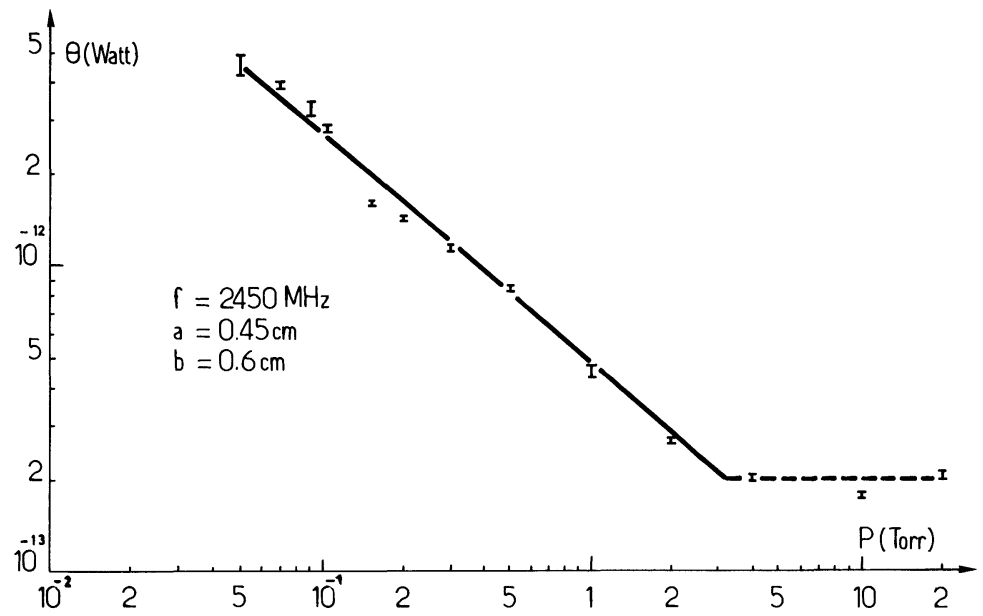

Fig. 4. $-\theta$ vs. pressure.

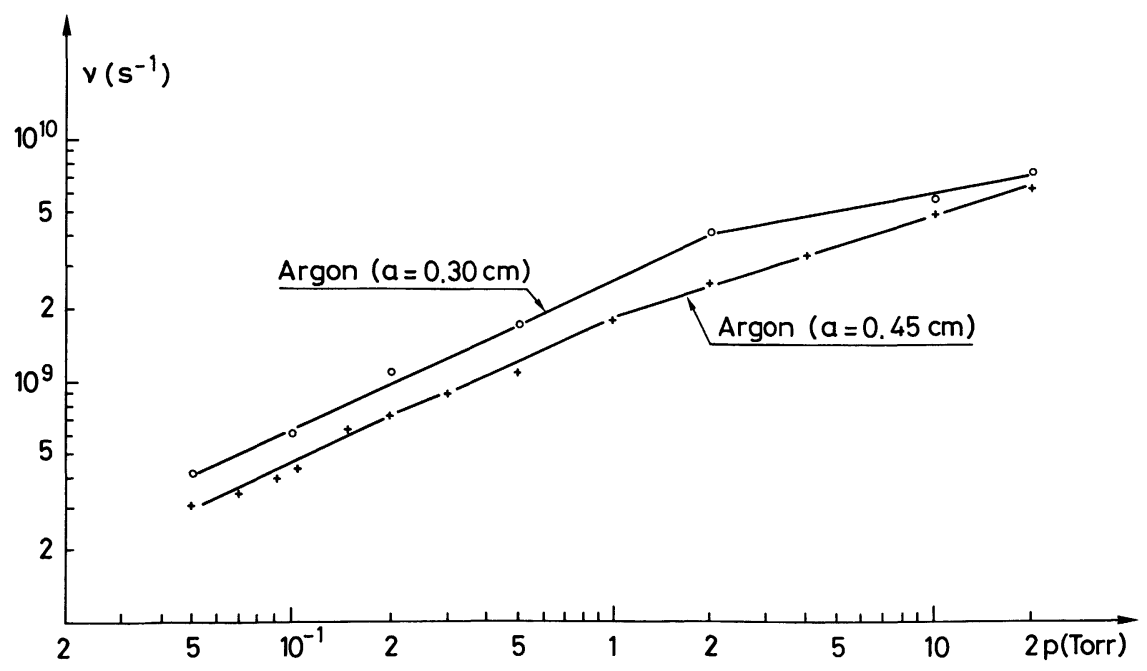

Fig. 5. - Electron collision frequency for momentum transfer vs. pressure for different tube radii. 


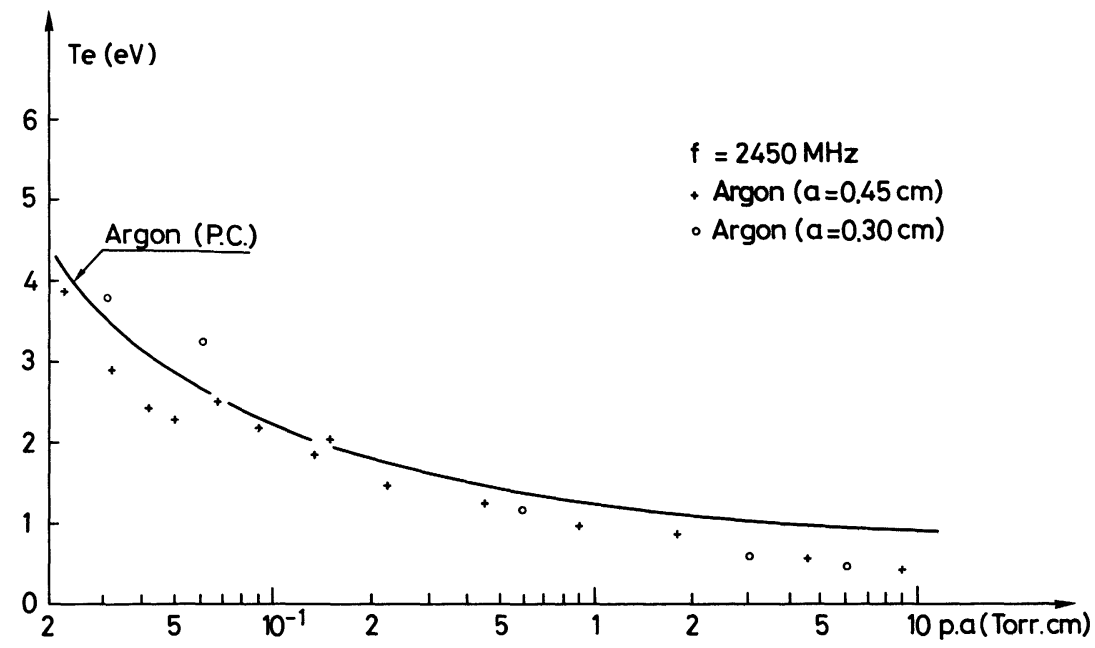

Fig. 6. - The dependence of electron temperature $T_{\mathrm{e}}$ on $p a$ where $p$ is the pressure and $a$, the tube radius; $(\longrightarrow) T_{\mathrm{e}}$ in the positive column.

It means that the microwave discharge is governed by the diffusion regime like for the positive columns. The discrepancy is presumably due to the fact that the gas temperature is higher than $300 \mathrm{~K}$ and we might take it into account to calculate the collision frequency and the electron temperature.

4. Conclusion. - The theoretical model verified here describes very well the axial electron density distribution along a plasma column sustained by the propagation of a surface microwave. It can be used to determine the energy balance and the collision frequency. Moreover this simple theory enables us to describe the surface wave parameters (electric field, power, electric energy...) along the plasma column.

This model makes it possible now to study the influence of the electric field on the discharge parameters.

\section{References}

[1] Moisan, M., Beaudry, C., Bertrand, L., Bloyet, E., Gagne, J. M., Leprince, P., Marec, J., MitChel, G., Ricard, A., ZaKrzewski, Z., IEE Conf. Publication 143 (1976) 382.

[2] Glaude, V. M. M., Moisan, M., Pantel, R., Leprince, P., Marec, J., J. Appl. Phys. 51 (1980) 5693.

[3] Chaker, M., Thesis, Orsay University (1981).

[4] Zakrzewski, Z., Moisan, M., Glaude, V. M. M., Beaudry, C., Leprince, P., Plasma Phys. 19 (1977) 77.

[5] Rogoff, G. L., M.I.T. Quart. Progress Rept. 90 (1968) 69. 